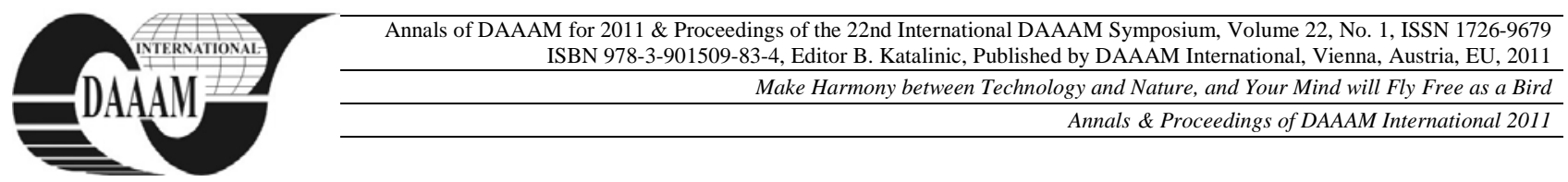

\title{
INJECTION MOLDING PROCESS AND ITS OPTIMIZATION
}

\author{
STANEK, M[ichal]; MANAS, M[iroslav]; MANAS, D[avid]; KYAS, K[amil]; \\ NAVRATIL, J[an] \& SENKERIK, V[ojtech]
}

\begin{abstract}
Optimization of injection molding process serves for finding ideal conditions during production of plastic parts and observing their dimensions, shapes and properties. It is possible to determine the appropriate injection pressure, velocity, value and time of packing pressure, etc. by optimization. The paper is dealing with description of Moldflow Plastics Xpert (MPX) system and its usage in optimization of injection molding process on real part during its production.

Key words: injection molding, optimization, process, mold
\end{abstract}

\section{INTRODUCTION}

Injection molding represents the most important process for manufacturing plastic parts. It is suitable for mass producing articles, since raw material can be converted into a molding by a single procedure. Typical injection moldings can be found everywhere in daily life; examples include toys, automotive parts, household articles and consumer electronics goods.

Moldflow Plastics Xpert (MPX) is a software and hardware solution that interfaces directly with injection molding machine controllers on the shop floor. MPX combines process setup, real-time process optimization, and production control according to set process parameters in one system. MPX is an advanced control solution for the automatic setup, optimization and monitoring of the process window of an injection molding machine. Unlike other control solutions, MPX can utilize the advanced simulation capabilities of Moldflow Plastics Advisers (MPA) and Moldflow Plastics Insight (MPI) software to provide an initial process configuration. MPX interfaces directly with the injection molding machine and provides online process correction with technology developed exclusively for the plastics injection molding industry. Nowadays, molding machine operators can consistently and systematically set up the process, perform an automated DOE (design of experiments) to determine a robust processing window, and automatically correct the process whether it should be drifted or go out of control during production. (Rees, 2002)

The optimization process consists of three main parts:

- Process Setup allows users to automate the setup of the injection molding process through a series of velocity and pressure-phase setup routines designed to fix molded part defects systematically. The objective is to achieve a combination of processing parameters which results in one good molded part.

- Process Optimization easily allows users to run an automated design of experiments (DOE) to determine a robust, "good parts" processing window that will compensate for normal process variation and ensure that acceptable quality parts are produced consistently.

Process Control is designed to maintain the optimized processing conditions determined with Process Optimization, resulting in reduced reject rates, higher part quality, and more efficient use of machine time. Process Control can automatically correct the process - either be drifted or go out of control and also can send relay signals to alarm operators or to divert suspect parts. (Stanek et al., 2006)

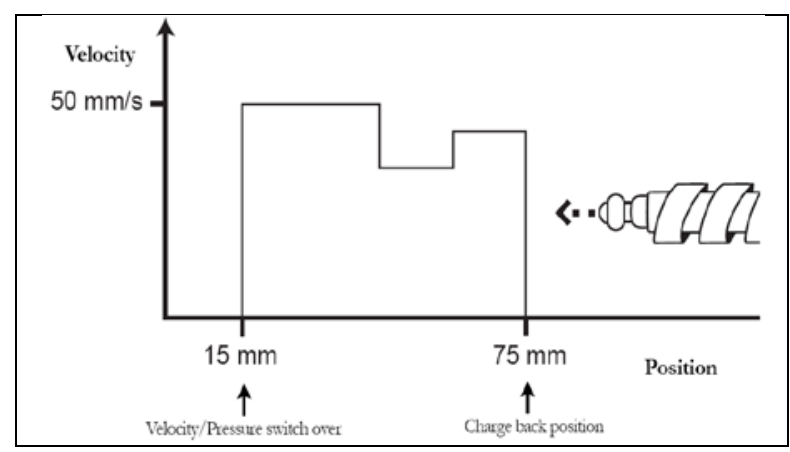

Fig. 1. Velocity profile example

\section{INJECTION MOLDING PROCESS OPTIMIZATION}

There will be description of injection molding process optimization procedure in the next chapters. It will be shown on the real chosen part usage MPX software and hardware directly connected to the injection molding machine Arburg Allrounder 420 C Advanced. (Stanek et al., 2009)

\subsection{Injection molded part - square piece}

The one-cavity injection mold with the cam pins was used for production of the molded part (square piece - Fig. 2.). The square piece is a part of the car assembly and it was used for fixing other parts in this car. The material of the produkt is copolymer PC+ABS.

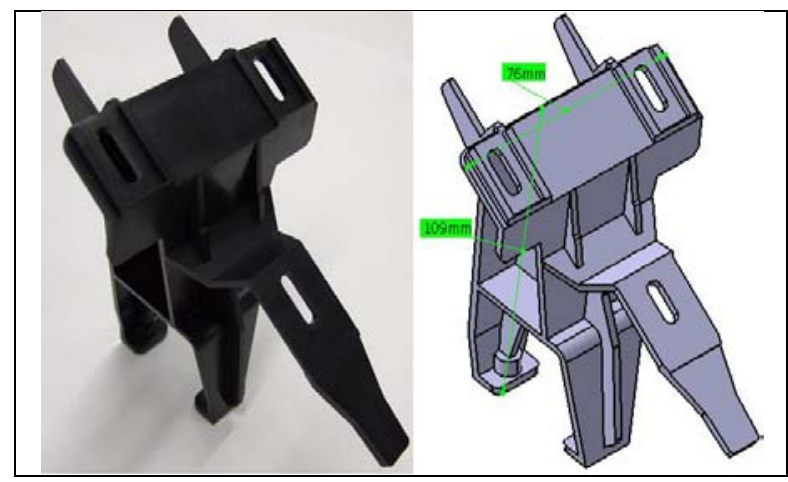

Fig. 2. Injection molded part - square piece

\subsection{Process settings taken from MPI analysis}

Injection molding process of the square piece has been analyzed in Autodes Moldflow Inside (AMI) software. The values (examples are shown on Fig. 3.) taken from this analysis has been used for comparison with optimized values and for upload to MPX software for next part of process optimization. 


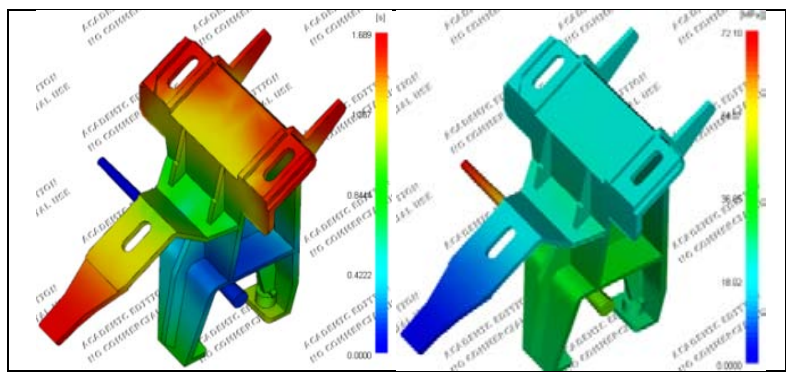

Fig. 3. Fill time - 1,689s (left), Pressure at end of fill - 7210 MPa (right)

The cooling of the injection mold has been made by circulating pure water with temperature $50^{\circ} \mathrm{C}$. Temperatures of the heating zones (injection unit of injection molding machine) are described in Table 1.

\begin{tabular}{|l|c|c|c|c|}
\hline Heating Zone & Feed & Transition & Metering & Nozzle \\
\hline Temperature $\left[{ }^{\circ} \mathrm{C}\right]$ & 235 & 250 & 255 & 265 \\
\hline
\end{tabular}

Tab. 1. Temperatures of heating zones

\section{RESULTS}

\begin{tabular}{|c|c|c|c|}
\hline & $\begin{array}{c}\text { Initial } \\
\text { Profile }\end{array}$ & $\begin{array}{c}\text { Final } \\
\text { Profile }\end{array}$ & Difference \\
\hline Velocity [mm/s] & 67 & 68 & \\
\hline $\begin{array}{c}\text { Displacement } \\
\text { (start - end) [mm] }\end{array}$ & $\begin{array}{c}10,9- \\
54,4\end{array}$ & $\begin{array}{c}18,8- \\
54,4\end{array}$ & \\
\hline Pressure [bar] & 1060 & 721 & \\
\hline Fill Time [s] & 0,65 & 0,52 & $-0,13$ \\
\hline Packing Pressure Time [s] & 6,43 & 8,4 & 1,97 \\
\hline Cooling Time [s] & 15 & 8,15 & $-6,85$ \\
\hline Total Time [s] & 22,08 & $\mathbf{1 7 , 0 7}$ & $-5,01$ \\
\hline
\end{tabular}

Tab. 2. Comparison of optimization results

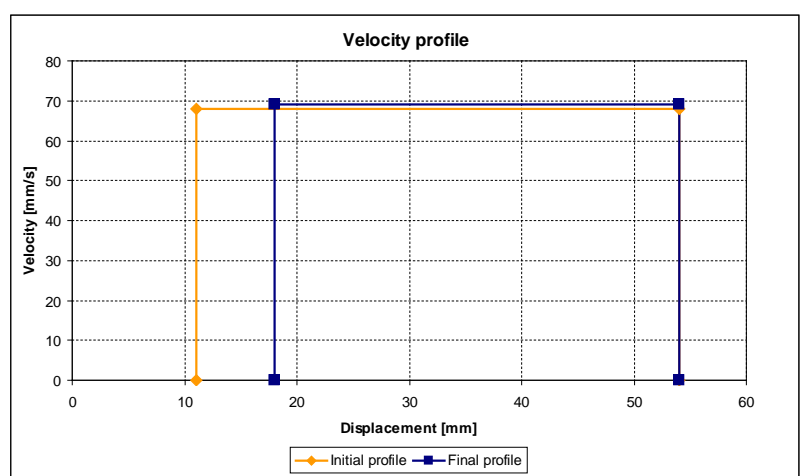

Fig. 4. Velocity profile

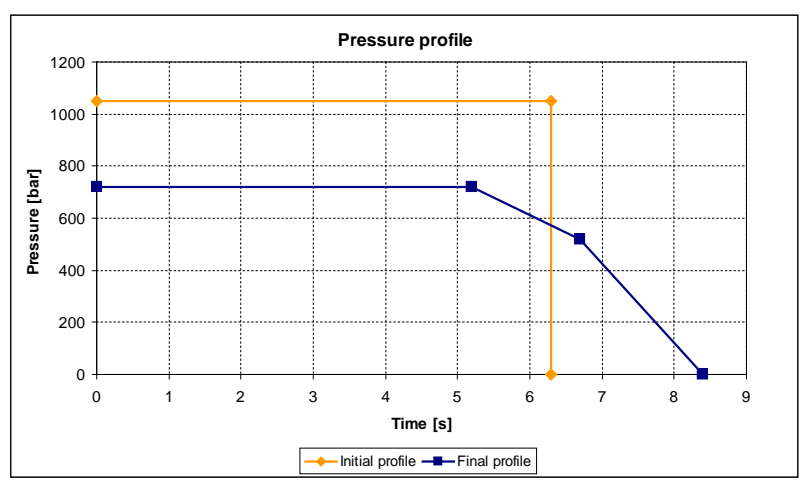

Fig. 5. Pressure profile
The changes of velocity and pressure profile (one is initial profile, other is changed profile) for each cycle of production are record in dialog box as is shown in Figure 6.

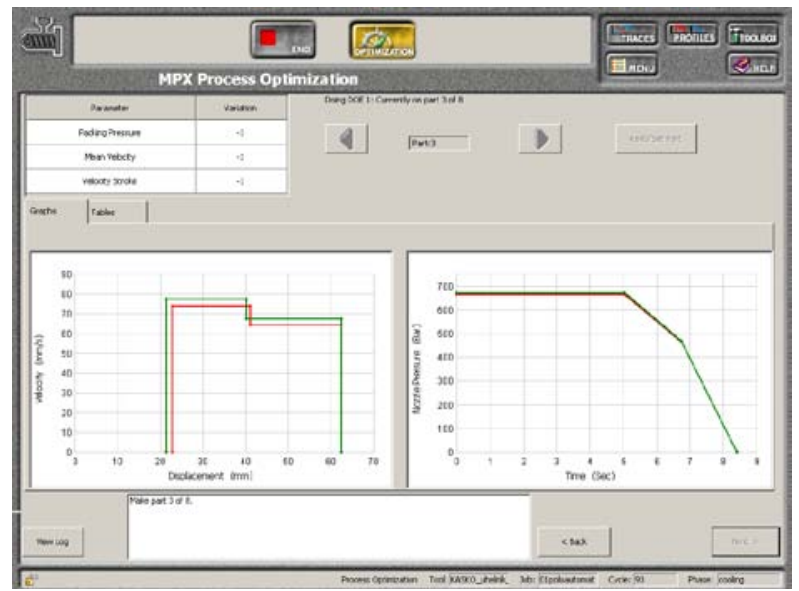

Fig. 6. Difference between profiles during optimization

\section{CONCLUSION}

This work deals with optimization of injecting cycle and using software MPX. The MPX system enables very effective optimization of the injecting process and ensures optimum process parameters leading to eliminating possible product defects. The aim of optimization is not only correct process conditions setting and eliminating all defects made during production, but also minimizing the total time of the injecting cycle which has a great economical impact. The research will continue with different molded part and different conditions.

\section{ACKNOWLEDGEMENTS}

This article is supported by the internal grant of TBU in Zlín No. IGA/10/FT/11/D funded from the resources of specific university research.

\section{REFERENCES}

Kyas K.; Stanek M.; Manas M.; Manas D.; Krumal M. \& Cerny J. (2010). DAAAM, p. 1081, ISSN 1726-9679, ISBN 978-3901509-73-5, Zadar, Croatia

Manas, D.; Stanek, M.; Manas, M.; Pata V. \& Javorik, J. (2009). Influence of Mechanical Properties on Wear of Heavily Stressed Rubber Parts, KGK - Kautschuk Gummi Kunststoffe, 62. Jahrgang, , ISSN 0948-3276, p.240-245

Rees, H. (2002). Mold engineering, Hanser Publishers, ISBN 3446-21659-6, Munich, Germany

Stanek, M.; Manas, M.; Manas, D. \& Sanda, S. (2009). Influence of Surface Roughness on Fluidity of Thermoplastics Materials, Chemicke listy, Volume 103, ISSN 0009-2770, p.91-95

Stanek, M.; Manas, M. \& Manas, D. (2009). Mold Cavity Roughness vs. Flow of Polymer, Novel Trends in Rheology III, AIP, ISSN 0094-243X, pp.75-85

Stanek, M.; Manas, M.; Drga, T. \& Manas, D. (2006) Polymer Fluidity Testing. 17th DAAAM, Vienna, Austria, p.395396, ISBN 3-901509-57-7

Stanek, M.; Manas, M.; Drga, T. \& Manas, D. (2006). Testing Injection Molds for Polymer Fluidity Evaluation, 17th DAAAM, Vienna, Austria, p.397-398,ISBN 3-901509-57-7

Stanek, M.; Manas, M.; Manas, D. \& Sanda, S. (2009). Plastics Parts Design Supported by Reverse Engineering and Rapid Prototyping, Chemicke listy, Volume 103, ISSN 0009-2770, pp.91-95 